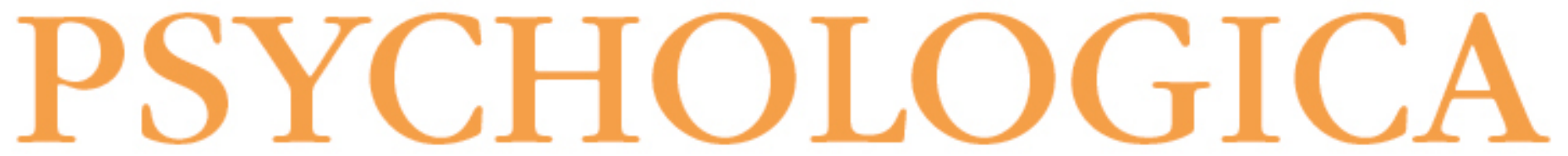

\title{
Sustentabilidade dos afetos: notas sobre a conjugalidade como dimensão de análise
} da família na contemporaneidade
Autor(es): $\quad$ Scorsolini-Comin, Fabio; Santos, Manoel Antônio dos
Publicado por: Imprensa da Universidade de Coimbra
URL
persistente:
URI:http://hdl.handle.net/10316.2/5539
DOI:
DOI:http://dx.doi.org/10.14195/1647-8606_53_12
Accessed : $\quad$ 26-Apr-2023 03:25:29

A navegação consulta e descarregamento dos títulos inseridos nas Bibliotecas Digitais UC Digitalis, UC Pombalina e UC Impactum, pressupõem a aceitação plena e sem reservas dos Termos e Condições de Uso destas Bibliotecas Digitais, disponíveis em https://digitalis.uc.pt/pt-pt/termos.

Conforme exposto nos referidos Termos e Condições de Uso, o descarregamento de títulos de acesso restrito requer uma licença válida de autorização devendo o utilizador aceder ao(s) documento(s) a partir de um endereço de IP da instituição detentora da supramencionada licença.

Ao utilizador é apenas permitido o descarregamento para uso pessoal, pelo que o emprego do(s) título(s) descarregado(s) para outro fim, designadamente comercial, carece de autorização do respetivo autor ou editor da obra.

Na medida em que todas as obras da UC Digitalis se encontram protegidas pelo Código do Direito de Autor e Direitos Conexos e demais legislação aplicável, toda a cópia, parcial ou total, deste documento, nos casos em que é legalmente admitida, deverá conter ou fazer-se acompanhar por este aviso. 
NÚMERO 53

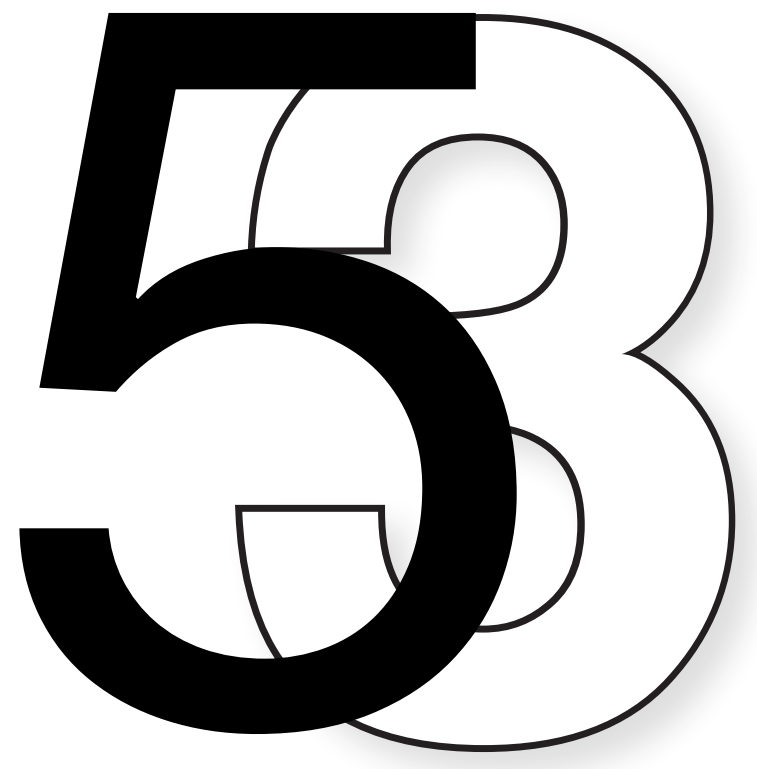

IMPRENSA DA UNIVERSIDADE DE COIMBRA

FACULDADE DE PSICOLOGIA E DE CIÊNCIAS DA EDUCAÇÃO DA UNIVERSIDADE DE COIMBRA 


\title{
Sustentabilidade dos afetos: Notas sobre a conjugalidade como dimensão de análise da família na contemporaneidade ${ }^{1}$
}

\author{
Fabio Scorsolini-Comin² \& Manoel Antônio dos Santos³
}

\begin{abstract}
O atual cenário de transformações socioculturais, impulsionado pela perda do interesse na vida pública, emancipação das minorias sexuais e o declínio dos meios tradicionais de doação de identidade (família, religião, pertencimento político, entre outros) fez com que restasse aos indivíduos apenas a identidade amorosa e a esperança de realização amorosa. Este artigo discute a conjugalidade como dimensão de análise da família. Pontua-se que esta noção, além de colocar em xeque a identidade construída por um casal em relação ou união, é também uma dimensão que contribui para as investigações acerca da família e suas vicissitudes. Aliada a uma leitura sociológica, o constructo da conjugalidade extrapola sua origem psicanalítica e incorpora aspectos contextuais, como a transição da conjugalidade para a parentalidade, a presença feminina no mercado de trabalho, a divisão do trabalho doméstico em casais de dupla carreira, escolaridade dos cônjuges, condições materiais de sobrevivência, políticas de incentivo ou de controle de natalidade, entre outros fatores. Postula-se que a sustentabilidade dos afetos deve ser uma prática desenvolvida no âmbito da família e nas formas de se fortalecerem vínculos estabelecidos, primando-se pelo engendramento de modos mais plurais e flexíveis de ser e de amar, compativeis com o ethos contemporâneo.
\end{abstract}

PALAVRAS-CHAVE: conjugalidade; família; gênero; relações conjugais; contemporaneidade.

\footnotetext{
1 Trabalho parcialmente subvencionado pela Coordenação de Aperfeiçoamento de Pessoal de Nível Superior (CAPES) e pela Fundação de Amparo à Pesquisa do Estado de São Paulo (FAPESP), com bolsa de doutorado concedida ao primeiro autor (Processo 2010/00244-9), sob orientação do segundo. Os autores também agradecem ao Conselho Nacional de Desenvolvimento Científico e Tecnológico (CNPq) pela bolsa de Produtividade em Pesquisa, nível 1D, concedida ao segundo autor.

2 Professor do Departamento de Psicologia do Desenvolvimento da Educação e do Trabalho da Universidade Federal do Triângulo Mineiro (UFTM), Ubenaba, MG, Brasil. Psicólogo, Mestre e Doutorando em Psicologia pelo Programa de Pós-Graduação em Psicologia da Faculdade de Filosofia, Ciências e Letras de Ribeirão Preto da Universidade de São Paulo (FFCLRP-USP-Brasil). Pesquisador do Núcleo de Ensino e Pesquisa em Psicologia da Saúde (NEPPS-CNPq-Brasil) - scorsolini_usp@yahoo.com.br

3 Psicólogo, Mestre e Doutor em Psicologia Clínica pela Universidade de São Paulo. Professor Associado da Faculdade de Filosofia, Ciências e Letras de Ribeirão Preto da Universidade de São Paulo (FFCLRP-USP-Brasil). Líder do Núcleo de Ensino e Pesquisa em Psicologia da Saúde (NEPPS-CNPq-Brasil). Bolsista de Produtividade em Pesquisa do CNPq - masantos@ffclrp.usp.br
} 


\section{O amor como um objeto fluido na ciência 4}

Em suma, vivemos numa moral dupla: de um lado, a sedução das sensações; de outro, a saudade dos sentimentos. Queremos um amor imortal e com data de validade marcada: eis sua incontornável antinomia e sua moderna vicissitude! Se pensarmos, no entanto, que as emoções não habitam as cavernas ou as clareiras das "essências emocionais", podemos renovar nossa gramática emotiva sem abrir mão dos ideais de amor que venhamos a reinventar (Costa, 1998, p. 21).

A escritora brasileira Adélia Prado escreve, em seu poema "Ensinamento", que o amor é uma "palavra de luxo", referindo-se ao fato de que sua mãe não Ihe havia mostrado a importância do amor. Para ela, este sentimento se tornou acessível apenas em um dado momento da vida. Ao contrário, a mãe havia Ihe revelado a importância dos estudos como um valor que poderia, também, ser transmitido no seio familiar. A "palavra de luxo", no entanto, está presente nos meios científicos desde as mais tenras investigações e especulações acerca do homem, sua existência e as formas de transmissão de valores, sentimentos e conhecimentos.

A sociedade, a cada época, promove modos preferenciais de subjetivação e, assim, fornece para os sentimentos e os comportamentos certas significações que guiam os modos de apreensão e interpretação dos fenômenos empíricos. $\mathrm{O}$ amor enquanto objeto de estudo fascina pesquisadores desde a Antiga Grécia, período no qual recebeu reflexões atentas por parte de filósofos como Platão e Aristóteles. Com o passar do tempo, outras disciplinas surgiram e também se dedicaram ao estudo do amor em suas diferentes manifestações, como é o caso da Psicologia e das Ciências Sociais. Na contemporaneidade, o amor se tornou uma categoria de análise do comportamento, de compreensão da família, e se introduziu nos domínios da Economia e da administração das finanças. O amor é temática recorrente nas campanhas de marketing, alvo da criação de produtos e responsável por parte substancial do faturamento das empresas em todo o mundo, o que ficou conhecido como "indústria do amor". Estima-se que o faturamento no dia dos namorados em 2010, por exemplo, tenha superado os 390 milhões de reais movimentados pela data em 2009, apenas pelo comércio eletrônico, no Brasil5. Desse modo, pode-se dizer que nossa sociedade não apenas não existiria sem o amor, como também não sobreviveria à modernidade e às novas formas de leitura de mundo que criamos a partir de e por este sentimento. Em termos da importância do amor, Torres (2000) destaca que esta "ideia” (ou o seu desejo) é relevante não apenas para a vida cotidiana de todos os cidadãos, mas também para a própria teoria sociológica. Resgatando o trabalho de Goode (1959), Torres

4 Segundo as normas do Novo Acordo Ortográfico, em vigência desde $1^{\circ}$ de janeiro de 2009. Este trabalho adota as normas da American Psychological Association (APA), 5 a edição.

5 Segundo pesquisa publicada pela Folha Online, em 05 de junho de 2009. Recuperada de < http:// www.designvirtual.com/?id=noticias\&idn=1504> em 21 de abril de 2010. 
(2000) afirma que o amor não configura apenas um sentimento presente na vida social, mas também uma força que predisporia à ação, tendo o poder de criar novas relações sociais.

O amor sempre esteve associado à felicidade ou à sua busca. Como destacado por Costa (1998), quando o amor romântico se instaurou como norma de conduta emocional na Europa, ele respondia a anseios de autonomia e felicidade pessoais. Sua associação com a vida privada burguesa fez com que ele se tornasse um elemento de equilíbrio entre a felicidade individual e o compromisso com os ideais coletivos, ou seja, era algo presente tanto na esfera da vida privada como na esfera da vida pública. Com o tempo, a hiperinflação do amor fez com este sentimento deixasse de ser um meio de acesso à felicidade para se tornar seu atributo essencial. Todo esse cenário de transformação, impulsionado pela perda do interesse na vida pública, a emancipação das minorias sexuais e o declínio dos meios tradicionais de doação de identidade (família, religião, pertencimento político, entre outros), fez com que restasse aos indivíduos apenas a identidade amorosa e a esperança de realização no campo afetivo-sexual.

Tal realização, notadamente na cultura ocidental, vem se dando a partir da união de duas pessoas, pelo casamento ou pela união consensual, ainda que o tema amor tenha evoluído, segundo pensadores como Bauman (2004), para um objeto de estudo fluido, que seria de difícil acesso e compreensão devido ao seu caráter mutável e frágil. Segundo este autor, cada vez mais os laços afetivos seriam caracterizados por essa fragilidade, pelo apreço pelo efêmero e pela fugacidade das alianças e formas de compromisso estável. O ser humano priorizaria os relacionamentos em "redes", podem ser tecidas ou desmanchadas com igual facilidade - e, frequentemente, sem que isso envolva nenhum contato além do virtual -, fazendo com que não saibamos mais manter laços a longo prazo. Embora o senso comum destaque que cada vez menos as pessoas buscam o casamento como forma de realização pessoal, observamos um crescimento nas taxas de casamentos e também de recasamentos, no contexto brasileiro, como destacado a seguir.

\section{Casamento à brasileira}

Segundo dados recentes do Instituto Brasileiro de Geografia e Estatística (IBGE), em 2006 o total de casamentos no Brasil foi de 889.828 , número $6,5 \%$ maior do que o apurado no ano anterior. Em 2007, houve 916.006 casamentos, confirmando a tendência de crescimento que vem sendo registrada no país desde 2002 (IBGE, 2008). Pessoas casadas de ambos os sexos relatam mais felicidade do que aquelas que nunca casaram ou são divorciadas, separadas ou viúvas. Pessoas que coabitam 
com um parceiro também são significativamente mais felizes em algumas culturas do que aquelas que vivem sozinhas (Diener \& Lucas, 2000; Lee, Seccombe, \& Shehan, 1991; Seligman, 2002). A relação entre bem-estar subjetivo e ser casado se aplica a pessoas de todas as idades, níveis de renda e graus de instrução, bem como origens racial-étnicas, sendo a qualidade conjugal associada positivamente ao bem-estar pessoal (Snyder \& Lopez, 2009).

Para Durham (1983), é característico das famílias humanas, em todas as sociedades, o estabelecimento de vínculos sociais que são criados por meio de representações (ideias, sistemas e símbolos) incorporadas nas noções de parentesco e instrumentalizadas pelo casamento. Ainda para esta autora, o casamento passa ser definido como um mecanismo, regulado pelo tabu do incesto, que atribui responsabilidades e direitos específicos sobre a prole de uma mulher a homens determinados, que mantêm em relação a ela os vínculos básicos e antagônicos de irmão e marido, privilegiando um desses termos ou estabelecendo a complementaridade entre eles.

Apenas para um breve resgate histórico, na Antiguidade o casamento estava voltado exclusivamente para a procriação, sendo considerado um bem. A moral cristã, a partir dos séculos XII e XIII, sacramentalizou o matrimônio, fato que foi acompanhado de uma explosão discursiva em relação ao desejo. Cada vez mais, a Igreja impunha a relação carnal como obrigatória no casamento, sem a qual ele não teria sentido, condenando todo e qualquer ardor no relacionamento entre os cônjuges, punindo os "excessos" e disciplinando pela interdição imposta por certas regras na interação conjugal, ao mesmo tempo em que incentivava a função procriadora (Casey, 1992; Vainfas, 1986).

A Igreja introduziu no casamento os valores da ascese e da caridade, equilibrando o mal (representado pela cópula) com o bem (representado pela oração e pela ideia do coito procriativo) e fazendo do matrimônio um estado de comunhão. De acordo com Vainfas (1986), o amor no casamento só era considerado "verdadeiro" quando submetido à disciplina da contingência, com a constituição de um "modelo cristão" no qual havia a reprovação da discórdia no interior do casal, a supressão da diferença e eliminação da alteridade entre os esposos, salvo no tocante ao poder marital. Portanto, o sentimento amoroso, tal como ocorre na relação entre indivíduos distintos e diferenciados sexualmente, comportando atração e igualdade entre os parceiros, estava ausente da concepção cristã de amor conjugal.

Para Vainfas (1986), a partir do final do Império Romano, o casamento apresentava sinais de maior frequência e estabilização enquanto prática social, vinculado à formação de uma descendência e à transmissão do patrimônio, mas já denotava a crescente importância do vínculo conjugal. Na Europa pré-moderna, a maioria dos casamentos era negociado por razões econômicas, emergindo ideias amo- 
rosas fortemente ligadas aos valores morais do cristianismo. O amor romântico, que emerge a partir do final do século XVIII, conciliava amor e liberdade como "estados normativamente desejáveis" (Giddens, 1993, p. 27). Na modernidade, a razão não tem espaço para a emoção, embora a vida emocional seja efetivamente reordenada nas condições variáveis das atividades cotidianas. Para Badinter (1985), no século XVIII, a felicidade não é mais apenas uma questão individual, mas um projeto que se espera realizar a dois, enquanto se aguarda a possibilidade de vivê-la com a coletividade. É neste período histórico que toma corpo a concepção de que, para que as relações entre o casal e os filhos sejam felizes, é preciso que sejam fundadas no amor-amizade.

Mesmo no Brasil, segundo Costa (1983), durante o período colonial os casamentos eram celebrados sob a égide das razões ou interesses familiares. Era uma decisão tomada unilateralmente pelo responsável, impondo ao dependente a obrigação de casar sem levar em conta sua própria opinião. O casamento não celebrava o reconhecimento social da união amorosa entre indivíduos, visto que o amor não era um pressuposto necessário à ligação conjugal. A vertente sentimental do casamento era sufocada por razões econômicas, interesses sociais e preconceitos raciais. Segundo Costa (1983), a representação religiosa do casamento e do amor profano colaborou para a ausência de substrato afetivo na constituição do casal. O catolicismo via no amor conjugal uma ligação que parecia roubar de Deus a devoção que lhe era devida.

No período colonial, o casamento passa a ser percebido sob a marca da higiene, ou seja, o cuidado com a prole converteu-se no paradigma da união conjugal. No casamento higiênico, a hereditariedade substituía a herança, sendo que o dinheiro e o status social herdados só mereciam reverência quando aliados a uma boa saúde física e boa constituição moral. A higiene encarnava o aburguesamento geral da sociedade brasileira oitocentista (Costa, 1983). Neste período, o amor desempenhava a tarefa de criação e regulação de novos papéis sociais do homem e da mulher no casamento. $O$ amor servia tanto como referência para a construção dos modelos de conduta social masculina e feminina quanto para atenuar as tensões conjugais nascidas da nova discriminação social dos sexos, regulando a harmonia entre marido e esposa.

Pensando nas diferenças entre os gêneros, no início da modernidade, de acordo com Giddens (1993), as mulheres concebiam uma ligação quase inevitável entre amor e casamento. Foi somente na segunda metade do século xx que o movimento feminista ofereceu outros caminhos para essa questão. A separação entre o casamento e suas raízes tradicionais impôs-se mais intensamente sobre as mulheres do que sobre os homens, que poderiam encontrar no casamento e na família, antes de tudo, um refúgio do individualismo econômico. 
Para os homens, ainda que a parentemente, o amor permanecia mais próximo do chamado amour passion. Giddens (1993) afirma que, desde o início das transformações que afetam o casamento e a vida pessoal, os homens em geral excluíram-se do desenvolvimento do domínio da intimidade. O vínculo entre o amor romântico e a intimidade foi suprimido e o apaixonar-se permaneceu intimamente ligado à ideia de acesso a mulheres cuja reputação era protegida até a santificação do casamento.

Giddens (1993) afirma que, na modernidade, os ideais do amor romântico tendem a fragmentar-se sob a pressão da emancipação sexual e da autonomia feminina, o que faz emergir o amor confluente, conceito que se opõe às qualidades de "para sempre" "único e exclusivo" do complexo do amor romântico. O amor confluente presume igualdade emocional na ligação amorosa, o que exige uma postura de abertura constante ao outro. É um ativo e contingente, o que confronta com a máxima romântica que pressupõe assimetria, submissão doméstica e identificação projetiva.

Para Cicco, Paiva e Gomes (2005), o estudo da família e dos modelos de relações conjugais introduzidos na pós-modernidade é fundamental para a compreensão das mudanças ocorridas nas últimas décadas e de suas implicações para o desenvolvimento e amadurecimento dos indivíduos nos contextos familiares atuais. Na visão da terapia de casal proposta por Costa (2007), o casamento é ainda um grande sonho que todo indivíduo, desde a infância, almeja realizar. No entanto, no caminho traçado até o encontro com a felicidade conjugal, surgem inúmeros obstáculos impostos pelas vicissitudes da vida e pelos problemas emocionais humanos. Assim, o casamento representaria uma das formas possíveis de o indivíduo amar outra pessoa e realizar-se sexualmente, enquanto a família cumpriria a indispensável e primordial função de conferir, àqueles que educa, uma identidade.

Atualmente, concebe-se que o casamento pode ser um espaço de desenvolvimento das individualidades, caso ofereça a oportunidade de operar um processo de individuação entre os parceiros (Féres-Carneiro, 1998; Gomes, \& Paiva, 2003). Estas pesquisas partem da noção de que o self não pode se desenvolver no isolamento e de que o eu é definido pela sua diferenciação com o tu, de modo que o tu constitua o alicerce que dá sustentação à identidade do indivíduo, desde que se possam diferenciar dois processos importantes presentes nas relações conjugais: a intimidade e a fusão. Para Costa (2005a), o amar e ser amado são condições para a construção do self e, consequentemente, para a capacidade de estabelecer relações de intimidade com os outros. Segundo Neyrand (2002) e Aboim (2006), o imaginário do casal é hoje marcado por tendências aparentemente contraditórias, que configuram o chamado paradoxo conjugal contemporâneo, o que significa que, por um lado, a unidade do casal estaria sedimentada cada vez mais por meio dos 
afetos, preterindo os aspectos patrimoniais, econômicos ou genealógicos, antes essenciais na sua institucionalização. Por outro, a individualidade tornar-se-ia crescentemente importante, ao ganhar independência face ao casal ou à família.

O desenvolvimento da intimidade de um casal requer a necessidade da existência de um "casamento interno", definido como uma capacidade de permitir que os opostos possam conviver dentro do self (Gomes, \& Paiva, 2003). Nesse horizonte de compreensão, a intimidade seria a capacidade de compartilhar o mais profundo ser com o outro, resguardando o lugar do diferente em cada um. O casamento real tanto deve promover como requerer essa capacidade, e as eventuais dificuldades maritais podem ser entendidas como um esforço para produzir esse "casamento interno" (Gomes, \& Paiva, 2003). Segundo Costa (2005a), as concepções afetivas da intimidade evidenciam a reciprocidade de sentimentos e perpassam a relação como um todo. Coexistem nesse campo duas linhas interpretativas: uma, que vê a intimidade como expressão de emoções e sentimentos positivos em relação ao companheiro e outra, que a concebe como parte de uma relação de amor.

\section{Da identidade à conjugalidade}

Aboim (2009), no domínio das ciências sociais, afirma que o tema "amor", embora possa ser considerado pelo senso comum como algo ligado exclusivamente a um par, a uma díade ou a um casal, é visto como necessário para a conceitualização da própria individualidade.

Féres-Carneiro (1998), uma das principais pesquisadoras da conjugalidade no Brasil, discute as mudanças e permanências de várias questões que se afiguram como centrais no casamento contemporâneo, como sua relevância institucional do mesmo e o papel que ele desempenha para os indivíduos como instrumento de construção nômica. Descreve como o casal contemporâneo é confrontado por duas forças paradoxais, ou seja, pelas tensões permanentes entre individualidade e conjugalidade. Para Féres-Carneiro (1998, 2003, 2008), o desafio de um casal reside, fundamentalmente, no fato de o casamento ou a união ser um palco no qual se devem se entrelaçar as individualidades de cada membro, operando-se a construção de um lugar em comum. O modelo único que cada par cria é denominado "absoluto do casal", conceito que determina os seus limites, ou seja, concebe o casal como uma entidade composta por duas pessoas e o seu modelo único. Para Féres-Carneiro (1998), este conceito recebe o nome de identidade conjugal, o que na literatura específica à área é designado como conjugalidade (Caillé, 1991; Cicco, Paiva, \& Gomes, 2005; Diniz-Neto, \& FéresCarneiro, 2005; Féres-Carneiro, 2003; Magalhães, \& Féres-Carneiro, 2003; Menezes, \& Lopes, 2007; Scorsolini-Comin \& Santos, 2011a,2011b). 
A palavra conjugalidade é um galicismo, mas seu uso tem sido referendado na língua portuguesa para recobrir o espectro das estruturas sociológicas pertinentes a uma vida a dois. Para Féres-Carneiro (1998), a conjugalidade define-se como dimensão psicológica compartilhada, que possui uma dinâmica inconsciente com leis e funcionamento específicos. A conjugalidade moderna pode ser resumida, segundo a visão sociológica de Heilborn (1995), como um núcleo de trocas afetivo-sexuais com uma não-demarcação de papéis conjugais. Nesta visão, o casal deve concentrar grande número de trocas em si, de modo a preservar a autonomia individual e a singularidade que a relação de amizade nesse contexto moral exibe.

Ainda na perspectiva sociológica, a conjugalidade ocorre em um dado momento do percurso pessoal de um significativo conjunto de indivíduos, "percurso esse social, cultural e ideologicamente marcado de forma diferenciada, de acordo com as condições de existência e com o gênero, já que é diferente também o que se considera ser o comportamento adequado para os dois sexos em setores sociais distintos" (Torres, 2000, p. 137). Sendo assim, não podemos pensar na conjugalidade sem considerar o contexto no qual essa noção é produzida e reproduzida.

O compartilhamento das dimensões individual e conjugal no relacionamento afetivo é um dos pilares nos quais se sustenta este conceito, na medida que envolve não apenas aquilo que pertence ao casal (construído pelo par), como aquilo que cada um traz ou agrega para a relação (construído pelo próprio membro da díade) e que permanece constante ao longo do tempo. Obviamente, a noção de conjugalidade vem evoluindo ao longo dos anos, o que desemboca na proposição mais contemporânea de Aboim (2009), que revela a existência de diferentes conjugalidades ou de diferentes modos de se experienciar e de se constituir o "nós conjugal", conceito que essa autora trata em termos da pluralidade dos afetos que estão em jogo na parceria. A noção de pluralidade desconstrói a explicação psicanalítica para o estabelecimento dos laços afetivos de modo unívoco ou centralizado em um único modelo de família. Em uma sociedade em constante movimento, como os afetos são plurais, a conjugalidade também o seria, o que traz à baila mais uma dificuldade para se apreender este fenômeno: ele está em plena transformação. Assim, não podemos mais tratar da conjugalidade como construto fixo e unicausal, o que se aplica também à família - o próprio conceito está em franco processo de mutação, como veremos a seguir.

\section{Casamento e conjugalidade: para compreender a família}

Segundo Diniz Neto e Féres-Carneiro (2005), ao contrário do que muitos pensam ou apregoam, a instituição casamento não se encontra em um processo agoni- 
zante. Pelo contrário, as pessoas estão em busca de padrões mais satisfatórios e funcionais de relacionamento amoroso, que propiciem condições mais favoráveis para o processo de diferenciação e desenvolvimento psicológico e emocional dos parceiros. Compreende-se que, na contemporaneidade, os padrões de conjugalidade devem estar abertos à transformação não apenas dos costumes, das formas de vinculação e dos fatores contribuam para que fazem com que um casal permaneça junto e experimente sentimentos de prazer e satisfação, mas também das pessoas e daquilo que as mesmas concebem ou avaliam como satisfação e bem-estar. Assim, não se deve apenas falar em transformações da conjugalidade ou da intimidade (Costa, 2005b; Giddens, 1993), mas transformações da própria percepção subjetiva de felicidade e bem-estar, seja no casamento ou em outros tipos de relacionamento humano.

Para Féres-Carneiro, Ziviani e Magalhães (2007), a conjugalidade, ao mesmo tempo em que re-edita o romance familiar, propicia a elaboração das vivências infantis. O encontro com o parceiro gera a oportunidade de metabolização e de desenvolvimento dos cônjuges, entrelaçando passado e presente, dentro de um projeto que pressupõe uma perspectiva de futuro a dois. Desde o momento da concepção, o sujeito está marcado pelo olhar dos pais, pelos seus ideais e pelos mitos familiares que se inscrevem e estruturam o desenvolvimento dos filhos desde as primeiras vinculações. Deste modo, a família teria um papel fundamental enquanto intermediária no processo de transmissão de valores, significados e percepções, na medida em que realça as possibilidades de transformação inerentes ao ato de transmitir e permite a construção da subjetivação (Magalhães, \& Féres-Carneiro, 2007).

Assim como ocorre nos planos da família e do casal, no âmbito individual o sujeito tem como tarefa construir, organizar e transformar suas heranças psíquicas, elaborando-as. Para Bertin e Passos (2003), com o nascimento dos filhos, o casal estrutura um grupo familiar, responsável pela escritura dos enredos que serão protagonizados pelas gerações que os sucederem. O desenvolvimento desses enredos pressupõe os investimentos recíprocos dos membros do grupo que continuarão a existir enquanto a criança prover suas expectativas de continuidade. Assim, pertencer a uma família, ou seja, ser considerado suporte de um discurso, oferece ao aparelho psíquico em vias de formação um alicerce, uma verdade inicial que sustenta o ingresso do sujeito na história. Este alicerce, por sua vez, possibilita a vivência de ser amado e reconhecido, e de ocupar um lugar em um mundo e uma ordem simbólica que o precede e o espera.

Bertin e Passos (2003) concluem que, no trabalho de transmissão psíquica na linha de sucessão das gerações, cada família transfere sua forma de entender e apreender o mundo externo, assim como de organizar o mundo interno. Na concepção de 
mundo interno do sujeito é preciso considerar também uma dimensão intragrupal, atual, e uma dimensão histórica constituída a partir de sucessivas gerações. Para Whitaker (1989) e Loriedo e Strom (2002), a relação de casal teria o valor de produzir profundas e necessárias modificações nas pessoas, notadamente porque permite a experiência nova de ingressar na família de origem do parceiro. Seligman (2002) a ponta para o fato de que o grupo familiar teria enorme importância não apenas na forma como os pais educariam seus filhos, mas também como seriam transmitidos valores, formas de agir e impressões subjetivas acerca do mundo, dos afetos e da própria família. Essa transmissão estaria no cerne do modo como as pessoas percebem sua satisfação com a vida e com seus relacionamentos.

Para Wagner e Falcke (2001), no conceito de satisfação conjugal estão implicadas tanto as experiências precoces do sujeito na sua família como os aspectos vivenciais da relação diádica atual, além das variáveis de personalidade e biodemográficas. A multiplicidade de variáveis e fatores presentes na tentativa de explicação do fenômeno amoroso e conjugal ocorre, principalmente, devido ao fato do casamento ser um momento em que se abre a porta da família para a entrada de um novo membro, oriundo de um outro sistema familiar. Nesse sentido, essa relação "não pode ser compreendida somente como uma união de dois indivíduos, pois representa a modificação de dois sistemas inteiros e uma sobreposição de ambos na criação de um terceiro subsistema" (Wagner \& Falcke, 2001, p. 3).

Essas autoras destacam que a formação do casal e, consequentemente, de uma nova família, se dá por meio do encontro dos sistemas de crenças das famílias de origem dos cônjuges. Assim, quando as pessoas se casam ou passam a viver em união conjugal, acontece o encaixe entre sistemas míticos de duas estruturas familiares diferentes, que formam um novo sistema baseado nos sistemas familiares de cada cônjuge. Como pontuado pelas autoras, o casamento ou a união constitui-se, então, em um processo que não é exclusivo do noivo e da noiva, ou do homem e da mulher. Ao contrário, "nele estão implicadas fortemente as famílias de origem de cada cônjuge, como transmissoras de um sistema mítico que precisa ser examinado e devidamente considerado na formação do casal" (Wagner \& Falcke, 2001, p. 5).

Assim, diferentes pesquisadores da Psicologia estudaram a influência da família de origem nas escolhas conjugais e na determinação dos motivos que levam as pessoas a elegerem um(a) ou outro(a) parceiro(a). Sendo por motivações conscientes ou não, pela introjeção dos modelos parentais ou pela repetição de padrões familiares, a importância das experiências com a família de origem é um fenômeno frequentemente considerado como a base dessa escolha (Wagner \& Falcke, 2001). Verifica-se, a partir das considerações dessas autoras, que a atração amorosa e sexual, o estabelecimento de vínculos afetivos, bem como as demais 
características das alianças estabelecidas entre o casal, provavelmente estejam subordinados às influências dos sistemas nos quais se formaram e estão inseridos ambos os parceiros.

Para Cruz (2005), as emoções parentais funcionam como uma espécie de barômetro, que refletiria a qualidade do ambiente familiar. Essa autora aponta que o afeto parental positivo prediz consistentemente resultados de desenvolvimentos favoráveis na criança e no adolescente futuramente, enquanto que a hostilidade parental está relacionada com resultados desenvolvimentais desfavoráveis. Pode-se observar então que, além da tendência de repetição dos padrões de relacionamento aprendidos, o casamento dos pais também pode ser considerado o modelo de relação conjugal no qual as pessoas se inspiram para modelar suas próprias relações amorosas. Por este motivo, o estudo da satisfação conjugal deve se colocar diante dessas considerações, abarcando essa dimensão. Nessa direção, cada cônjuge traz para o casamento tanto um modelo de interação aprendido, como também expectativas baseadas no que observou na relação de casal de seus pais. A partir dessas observações vivenciadas, cada um pode buscar relacionamentos similares quando aprovou o que viu, ou muito diferentes, quando desaprovou.

Pensando especificamente na satisfação auferida nos relacionamentos afetivos, Wagner e Falcke (2001) destacam que dificilmente um casal poderá estabelecer uma relação afetiva e sexualmente feliz se não tiver conseguido desenvolver uma boa autonomia em relação aos pais, que deve ser consolidada nos primeiros anos de relacionamento conjugal. Entretanto, essas autoras salientam que, como ninguém se separa totalmente de sua família de origem, por mais independente que seja, tanto emocional como economicamente, a atitude madura é caracterizada pela capacidade de evitar que as famílias dos cônjuges entrem em conflito, preservando o bom relacionamento entre ambas.

A satisfação nos relacionamentos de casal é um tema premente no campo das ciências humanas, o que revela sua atualidade e a complexidade teórica e metodológica que desafia os pesquisadores da área, embora a literatura aponte para um predomínio de estudos no âmbito do casamento, desconsiderando vinculações anteriores, como é o caso do namoro, que se caracteriza como uma relação com certa estabilidade e que se dá antes do casamento como uma forma de aproximação e de vivência afetiva (Scorsolini-Comin \& Santos, 2010). Na contemporaneidade, destaca-se que o namoro não possui mais um vínculo obrigatório com o casamento, como se dava antigamente, mas finalidade e significado próprios. No entanto, os estudos sugerem que o namoro se diferencia do "ficar", uma vez que envolve o estabelecimento de laços afetivos mais duradouros e regulados, na maioria das vezes, pela fidelidade, exclusividade, responsabilidade na promoção do bem-estar do outro e participação efetiva na vida do outro (Bertoldo \& Barbará, 2006; Chaves, 1993). 
Seligman (2002), amparado nos estudos de Bowlby (1969/1990) e de Ainsworth, Bell e Stayton (1992), destaca que é no berço da família e das primeiras experiências de vida que os filhos vão construindo não apenas as percepções iniciais acerca do mundo, como suas primeiras vivências em torno do que é a felicidade, o prazer e o bem-estar. Em estudo de Scorsolini-Comin (2009), foram encontradas correlações positivas e significativas entre a satisfação conjugal e o bem-estar subjetivo (BES). O BES é considerado o estudo científico da felicidade humana. O autor considera que a conjugalidade está diretamente relacionada ao nível de BES de cada um dos parceiros. Se considerarmos que a conjugalidade adulta é construída também a partir dos primeiros vínculos estabelecidos na família e, portanto, da conjugalidade dos pais tal como percebida pelos filhos, o nível de BES estaria relacionado também ao modo como cada parceiro percebe o relacionamento conjugal dos pais.

Assim, compreender a família e o modo como ela se constitui não apenas ao longo do processo histórico, como também na história de cada núcleo/arranjo familiar, são passos fundamentais para investigarmos a conjugalidade e seu processo de transmissão de valores, práticas e crenças, através das sociedades (Aboim, 2009; Torres, 2000).

\section{Considerações finais}

Ao final deste estudo, devemos destacar que a conjugalidade, mais do que uma noção que coloca em xeque a identidade construída por um casal em relação ou união, é também uma dimensão que contribui para as investigações acerca da família. Para o alcance pleno dessa meta são necessárias novas formulações teóricas e pesquisas empíricas. De que modo as famílias vêm estabelecendo vínculos e como estes interferem na própria construção da conjugalidade de seus filhos na vida adulta é uma pergunta de pesquisa ainda premente e que merece maior investigação, a partir de diferentes prismas. Como trazido por Aboim (2009) ao estudar os discursos femininos de portuguesas casadas, assim como não existiria apenas um modelo de família ou um modelo de família predominante em determinada camada social, haveria diferentes conjugalidades ou diferentes formas de organização e de desenvolvimento conjugal a depender das condições emocionais e também da vida concreta experimentadas pelos casais. É neste cenário que se abre a necessidade de compreensão mais global do fenômeno, relacionando-o com a transição da conjugalidade para a parentalidade, a presença feminina no mercado de trabalho, a divisão do trabalho doméstico em casais de dupla carreira, escolaridade dos cônjuges, condições materiais de sobrevivência, políticas 
de incentivo ou de controle de natalidade, entre outros fatores, como destacado no estudo de Lago et al. (2009).

Vivemos na era da sustentabilidade (social, econômica, financeira, ambiental), em que buscamos formas de retroalimentarmos nosso consumo, nossos recursos e nossas fontes de energia e de desenvolvimento, a fim de que não nos faltem tais elementos no futuro. Como trazido por Costa (2005b), o amor romântico, como prática cultural, está incorporado em um amplo leque de produtos, objetos, locais e rituais, o que nos permite considerar que a economia está imbricada em diversas esferas do amor e das demandas da sociedade contemporânea, promovendo a assunção de "produtos culturais que marcam os ideais e os sentimentos amorosos, além de contextos para a vivência dos rituais românticos" (p. 124).

Desse modo, é mister que busquemos também a sustentabilidade dos afetos, na medida em que possamos estabelecer vínculos não apenas mais duradouros, mas sobretudo mais saudáveis, menos liquefeitos e mais comprometidos com a construção de identidades que envolvam o contato com o outro e a produção coletiva de sentidos e práticas mais adaptativas em nossos relacionamentos. A sustentabilidade dos afetos deve ser uma prática desenvolvida no âmbito da família e nos modos de se fortalecerem vínculos já existentes, primando-se pelo estabelecimento de formas mais flexiveis e plurais de ser e de amar, que possam acolher as diferenças e estimular o desenvolvimento emocional.

A sustentabilidade dos afetos é um apontamento imprescindivel para que as relações possam amadurecer em um mundo no qual a mutabilidade é parte integrante e irrevogável do ethos contemporâneo, assim como o reconhecimento da pluralidade e do estado fluido dos relacionamentos. Que as afetividades ou conjugalidades plurais, como destaca Aboim (2009), possam, de fato, promover formas plurais de existência, de intersubjetivação e de desenvolvimento pessoal - eis o ideal a ser perseguido em um cenário em constante transformação.

\section{Referências}

Aboim, S. (2006). Conjugalidade, afectos e formas de autonomia individual. Análise Social, $41(180), 801-825$.

Aboim, S. (2009). Da pluralidade dos afetos: trajetórias e orientações amorosas nas conjugalidades contemporâneas. Revista Brasileira de Ciências Sociais, 24(70), 107-122.

Ainsworth, M. D. S., Bell, S. M., \& Stayton, D. J. (1992). Infant-mother attachment and social development: "Socialization" as a product of reciprocal responsiveness to signals. In M. Woodhead, R. Carr, \& E. Light (Eds.), Becoming a person (pp. 30-55). London: Routledge. Badinter, E. (1985). Um amor conquistado. Rio de Janeiro: Nova Fronteira. 
Bauman, Z. (2004). Amor líquido: Sobre a fragilidade dos laços humanos. São Paulo: Zahar.

Bertin, I. P., \& Passos, M. C. (2003). A transmissão psíquica em debate: Breve roteiro das concepções psicanalítica e sistêmica. Interações, 8(15), 65-79.

Bertoldo, R. B., \& Barbará, A. (2006). Representação social do namoro: A intimidade na visão dos jovens. PsicoUSF, 11(2), p. 229-237.

Bowlby, J. (1969/199o). Apego e perda: Apego - A natureza do vínculo. São Paulo: Martins Fontes, vol. 1.

Caillé, P. (1991). Un et un font trois: Le couple révélé à lui-même. Paris: ESF.

Casey, J. (1992). A história da família. (S. Bath, Trad). São Paulo: Ática.

Chaves, J. C. (1993). "Ficar com" a individualização: Um estudo sobre um código de relacionamento no Brasil. Dissertação de Mestrado não-publicada, Pontifícia Universidade Católica do Rio de Janeiro.

Cicco, M. F., Paiva, M. L., \& Gomes, I. C. (2005). Família e conjugalidade: o sintoma dos filhos frente à imaturidade do casal parental. Psicologia Clínica, 17(2), 53-63.

Costa, M. E. (2005a). À procura da intimidade. Porto, Portugal: Edições Asa.

Costa, S. (2005b). Amores fáceis: Romantismo e consumo na modernidade tardia. Novos Estudos, 73, 111-124.

Costa, G. P. (2007). O amor e seus labirintos. Porto Alegre: Artmed.

Costa, J. F. (1998). Sem fraude nem favor: Estudos sobre o amor romântico. Rio de Janeiro: Rocco.

Costa, J. F. (1983). Ordem médica e norma familiar. Rio de Janeiro: Graal.

Cruz, O. (2005). Parentalidade. Coimbra: Quarteto.

Diener, E., \& Lucas, R. E. (2000). Explaining differences in societal levels of happiness: Relative standards, need fulfillment, culture and evaluation theory. Journal of Happiness Studies, 1, 41-78.

Diniz-Neto, O., \& Féres-Carneiro, T. (2005). Psicoterapia de casal na pós-modernidade: Rupturas e possibilidades. Estudos de Psicologia, 22(2), 133-141.

Durham, E. (1983). Perspectivas antropológicas da mulher 3. Rio de Janeiro: Zahar.

Féres-Carneiro, T. (1998). Casamento contemporâneo: O difícil convívio da individualidade com a conjugalidade. Psicologia: Reflexão e Crítica, 11(2), 379-394.

Féres-Carneiro, T. (2003). Separação: O doloroso processo de dissolução da conjugalidade. Estudos de Psicologia, 8(3), 367-374.

Féres-Carneiro, T. (2008). Pesquisa e prática clínica: Construindo articulações teóricas. Psicologia: Reflexão e Crítica, 21(3), 349-355.

Féres-Carneiro, T., Ziviani, C., \& Magalhães, A. S. (2007). Questionário sobre a conjugalidade dos pais como instrumento de avaliação. In T. Féres-Carneiro, Família e casal: Saúde, trabalho e modos de vinculação (pp. 251-268). São Paulo, SP: Casa do Psicólogo.

Giddens, A. (1993). Transformações da intimidade: Sexualidade, amor e erotismo nas sociedades modernas. (M. Lopes, Trad.). São Paulo: Editora UNESP.

Gomes, I. C., \& Paiva, M. L. S. C. (2003). Casamento e família no século XXI: Possibilidade de holding? Psicologia em Estudo, 8(número especial), 3-9.

Goode, W. (1959). The theoretical importance of love. American Sociological Review, [s.n.].

Heilborn, M. L. (1995). O que faz um casal, casal? Conjugalidade, igualitarismo e identidade sexual em camadas médias urbanas. In I. Ribeiro, \& A. C. T. Ribeiro (Orgs.), Família em processos contemporâneos? Inovações culturais na sociedade brasileira (pp. 91-128). São Paulo: Loyola. 
Instituto Brasileiro de Geografia e Estatística (2008). Estatísticas do Registro Civil: Casamentos no periodo de 2003 a 2007. Recuperado de <www.ibge.gov.br/brasil_em_sintese/ populacao11.htm>, em 10 out. 2009.

Lago, M. C. S., Souza, C. D., Kaszubowski, E., \& Soares, M. S. (2009). Gênero, gerações e espaço doméstico: Trabalho, casa e família. Paideia, 19(44), 357-366.

Lee, G. R., Seccombe, K., \& Shehan, C. L. (1991). Marital status and personal happiness: An analysis of trend data. Journal of Marriage and the Family, 53, 839-844.

Loriedo, C., \& Strom, P. (2002). Os processos de transmissão geracional nos casais e o tratamento das problemáticas ligadas às famílias de origem. In M. Andolfi (Org.). A crise do casal: Uma perspectiva sistêmico-relacional (pp. 123-138). (L. Kahl, \& G. Menegoz, Trad.). Porto Alegre: Artmed.

Magalhães, A. S., \& Féres-Carneiro, T. (2007). Transmissão psíquica geracional: Um estudo de caso. In T. Féres-Carneiro (Org.). Familia e casal: Saúde, trabalho e modos de vinculação (pp. 341-364). São Paulo: Casa do Psicólogo.

Menezes, C. C., \& Lopes, R. C. S. (2007). A transição para o casamento em casais coabitantes e em casais não-coabitantes. Revista Brasileira de Crescimento e Desenvolvimento Humano, 17(1), 52-63.

Neyrand, G. (2002). Idéalisation du conjugal et fragilisation du couple ou le paradoxe de l'individualisme relationnel. Dialogue, 155, 80-88.

Rosa, G. (1998). Primeiras estórias. Rio de Janeiro: Nova Fronteira.

Scorsolini-Comin, F. (2009). Casar, verbo (in)transitivo: Bem-estar subjetivo, conjugalidade e satisfação conjugal na perspectiva da Psicologia Positiva. Dissertação de Mestrado, Universidade de São Paulo, Ribeirão Preto, SP. Recuperado de < http://www.dominiopublico.gov.br/pesquisa/DetalheObraForm.do?select_action=\&co_obra=153753> em 21 abr. 2010.

Scorsolini-Comin, F. \& Santos, M.A. (2010). Satisfação conjugal: reunião integrativa da literatura científica nacional. Psicologia: Teoria e Pesquisa, 26(3), 525-531.

Scorsolini-Comin, F. \& Santos, M.A. (2011a). Casamento e satisfação conjugal: Um olhar da Psicologia Positiva. São Paulo: Annablume e FAPESP/Brasília: CNPq.

Scorsolini-Comin, F. \& Santos, M.A. (2011b). Ajustamento diádico e satisfação conjugal: correlações entre os domínios de duas escalas de avaliação da conjugalidade. Psicologia: Reflexão e Crítica, 24(3), 439-447.

Seligman, M. E. (2002). Authentic happiness: Using the new Positive Psychology to realize your potential for lasting fulfilment. London: Nicholas Brealey Publishing.

Snyder, C. R., \& Lopez, S. J. (2009). Psicologia Positiva: Uma abordagem cientifica e prática das qualidades humanas. (R. C. Costa, Trad.). São Paulo: Artmed.

Torres, A. (2000). A individualização no feminino, o casamento e o amor. In C. E. Peixoto, F. de Singly, \& U. Cicchelli (Orgs.), Família e individualização (pp. 135-156). Rio de Janeiro: Fundação Getúlio Vargas.

Vainfas, R. (1986). Casamento, amor e desejo no ocidente cristão. São Paulo: Ática.

Wagner, A., \& Falcke, D. (2001). Satisfação conjugal e transgeracionalidade: Uma revisão teórica sobre o tema. Psicologia Clínica, 13(2), 1-15.

Whitaker, C. A. (1989). Considerazioni notturne di un terapeuta della famiglia. Roma: Astrolabio. 


\section{Sustainability of affect: Notes on conjugality in dimension of the analy- sis of the contemporary family}

Current cultural and social transformations, pressed by loss of interest in public life, emancipation of sexual minorities and the decline of traditional ways of identity donation (family, religion, political life, and others) made to individuals that remained only love identity and the trust in love realization. The aim of this paper is to discuss the conjugality how part of family analysis. Points out that this notion, also ask about the built of identity by a couple in relationship, is a dimension that contributes to the investigations about the family and its trials. Together with the sociologic context, the construct of marital psychotherapy extrapolates its origin and incorporates contextual aspects, such as marital transition to parenthood, women's presence in the labor market, the division of housework in dual-career couples, the spouses' education, material conditions of survival, incentive policies or birth control, among other factors. It is postulated that the sustainability of affection should be a practice developed within the family and ways to strengthen links established, excelling themselves by engendering more varied and flexible ways of being and loving, compatible with the contemporary ethos.

KEY-WORDS: conjugality, family, gender; marital relations; contemporaneity.

\section{La durabilité de l'affect: Notes sur la conjugalité dans la dimension de l'analyse de la famille contemporaine}

Les transformations culturelles et sociales, pressé par une perte d'intérêt dans la vie publique, l'émancipation des minorités sexuelles et le déclin des méthodes traditionnelles de don d'identité (la famille, la religion, la vie politique, et d'autres) aux personnes qui ne restait plus que l'amour d'identité et de la confiance dans la réalisation amour. Le but de cet article est de discuter de la conjugalité comment une partie de l'analyse de la famille. Souligne que cette notion, également des questions sur la construction de l'identité par un couple dans la relation, est une dimension qui contribue à des enquêtes sur la famille et de ses épreuves. Avec le contexte sociologique, la construction de la psychothérapie conjugale extrapole son origine et incorpore des aspects contextuels, tels que la transition conjugale à la parentalité, la présence des femmes au marché du travail, le partage des travaux domestiques dans les couples à double carrière, l'éducation des époux, les conditions matérielles de survie, les politiques d'incitation ou de contrôle des naissances, entre autres facteurs. II est postulé que la durabilité de l'affection doit être une pratique développée au sein de la famille et les moyens de renforcer les liens établis, se dépasser en engendrant des moyens plus variés et souples d'être et d'aimer, compatible avec la philosophie contemporaine.

MOTS-CLÉS: Conjugalité, Famille; Sexe; Relations conjugales; Contemporanéité. 